\title{
SUSTAINABLE ENERGY FOR SMART CITY
}

\author{
L.D. GITELMAN, M.V. KOZHEVNIKOV \& L.A. ADAM \\ Department of Energy and Industrial Management Systems, Ural Federal University, Russia.
}

\begin{abstract}
The article presents the results of a study of structural changes in the energy sector serving digital technologies for the urban environment of the future that is being created now. The study considers country-specific factors and problems of ensuring the sustainability of heat and power supply.

The authors look at the priority areas of a new phase of electrification aimed at the development of advanced energy-saving smart technologies, electric transport, electric cars and appropriate energy and utility infrastructure.

The case is studied of developing engineering, technical, organizational and economic solutions when overhauling the heat supply system in a 'smart' residential district of Yekaterinburg, one of Russia's megalopolises, that is being designed and constructed on the basis of the principles of intelligent engineering infrastructure.

Keywords: smart city, sustainable energy, Smart Grid, electrification, heat supply, electric vehicles, electric heating.
\end{abstract}

\section{INTRODUCTION}

The defining features of a smart city is a highly efficient economy and effective management, high living standards, a dynamic business climate and labor mobility, a caring attitude towards the environment and people who are actively involved in the life of the city. In this regard, the smart city is a product of a partnership of business, authorities and scientists that creates a platform for knowledge exchange, collaborative learning and long-term innovation projects. Building a new smart city (or transforming a conventional city into a 'smart' one) means, on the one hand, its vertical hyperconnectivity, which shows in a high density of information systems within the urban infrastructure that enable its continuous remote monitoring, analysis and parameter control. On the other hand, the quality of the living environment, including clean water and air quality, access to transport services, good transport networks, safety and security is of critical importance [1-4].

A review of the literature on the subject of smart city development [5-11] shows that the electric power industry, or, more specifically, the way it adapts to the demands of proactive consumers plays a key role in the efficiency of such major projects. The degree of its adaptation largely depends on the depth of electrification that makes it possible to provide a wide range of ancillary energy services. For example, Meijer and Bolivar [11] point out that a bulk of authors investigating the subject of smart city development with a technological focus emphasize energy technology and Smart Grids. This is due to the fact that electricity is the greenest and easiest-to-control energy carrier.

Radical transformations that are taking place in the energy infrastructure of big cities under the influence of smartization and its integration with the utilities sector as a whole determine the new requirements to stability of the energy sector. In this context, it is appropriate to make a distinction between stable functioning and steady development.

Stable functioning indicates the ability of the sector to meet the national or regional economy's dema nd for electricity and capacity while ensuring the necessary level of reliability, quality and sustainability of power supply at a price that is acceptable to consumers and producers. This mode envisages the limited introduction of new capacity for the purposes of 
reserve and renewal of fixed assets, an increase in transmission network capacity, and improvements to operational and dispatch control systems.

Steady development is about the expansion of power supply, including by means of new capacity, in order to support economic growth and electrification. Steady development is measured by the volume and speed of the adoption of industry-specific innovations and subsequent qualitative transformations of the energy sector (such as optimization of fuel and energy balance, digitization, development of small-scale electricity generation, researchintensive services). It is worth noting that steady development is impossible without ensuring the stable functioning of the electric power industry, but it is the steady development of the electric power industry that is both a condition for and a result of a technological breakthrough in the economy [12].

The study analyzes the key features of the energy sector in smart cities, instruments for ensuring its stable functioning and steady development. It considers the case of the Akademichesky residential district of Yekaterinburg, one of the first residential developments in Russia designed on the principles of smart engineering infrastructure, as an example of the practical application of advanced technologies for building electricity and heat supply systems.

\section{DRIVERS OF ENERGY SECTOR DEVELOPMENT IN SMART CITIES: INTEGRATED UTILITIES INFRASTRUCTURE, ELECTRIC TRANSPORT, ELECTRIFICATION}

A 'smart city' needs to address the problem of building its infrastructure on the basis of new technologies that are capable of the rational use of energy sources and a minimum impact on the environment $[13,14]$. This calls for new solutions in the fields of power engineering, heat and water supply, energy accounting, waste disposal, as well as the creation of a more efficient transportation system and construction of 'smart buildings'. Additionally, energy exchange in a smart city needs to be balanced by means of the smart grid - an automated self-manageable system that can receive electric power and transform it into an end product with minimum human involvement (Fig. 1).

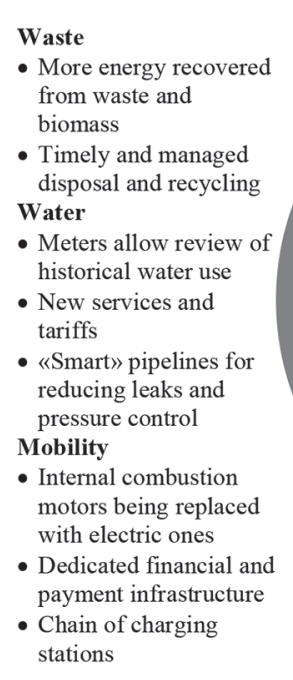

Figure 1: Integrated energy system of 'a smart city'.
Stakeholders (consumers, utilities, regulators)

Electricity

- Historical and current consumption data available

- Time-of-use rates

- Automated demand side management Heating

- Wider use of micro-CHP

- New materials for reducing heat transfer losses

- Solar heating

Buildings

- «Smart» energy supply, lighting, climate systems

- Self-

sustainingpowerg eneration 
Smart cities, therefore, make a transition to integrated models of energy supply in which separate schemes of energy, heat, gas and water supply and telecommunication structures form one 'system of systems' that is capable of balancing power generation and consumption and of drastically reducing generation capacity by cutting consumption peaks, thus producing a cumulative effect for other participants in the energy market.

The cases of such megalopolises as Barcelona, San Francisco, Amsterdam, Singapore show that the configuration of the electric power industry plays a defining role in attaining the key goals of the steady development of a city - from minimization of harmful emissions to Internet-based control of urban systems [15-18].

Electrification as the process of powering the economy by electricity, the most advanced energy carrier, is a critical factor in achieving the required stable configuration by the energy sector. This definition emphasizes the integrity of the electricity consuming and power generating spheres.

Each of these spheres are at different levels of preparedness (a combination of prerequisites) for electrification. Demand for electrification is determined by the energy consuming system. Its preparedness is a function of motivation for embracing innovative electrical technologies, access to them and investment capital. Other prerequisites are a certain price ratio between electricity and alternative energy carriers, a drive for energy conservation (aimed at reducing electric power consumption and, consequently, electricity bills), governmentprovided incentives for cutting costs, adaptation of the market of electricity and capacity to electrification, especially in regard to competition in generation.

The preparedness of the power generating system implies the availability of the sufficient amount of generating capacity that is synchronized by time and place of load coverage, the reliability and quality of power supply, energy efficient technologies and prices that induce electrification.

The studies described in $[19,20]$ point to a new phase of electrification in the context of smart cities. The phase includes non-power intensive areas, such as:

- qualitative changes in energy consuming household processes and considerable expansion of the range of smart appliances;

- growing use of electric vehicles and expansion of the innovative supporting infrastructure;

- widespread use of information and communications equipment as an electrified process.

Additionally, higher levels of electrification in a smart city occur together with the introduction of multi-agent control of energy information systems [21, 22]. This triggers the emergence of a wide range of internal and external research-intensive services in the energy sector of the region:

- remote monitoring of equipment and engineering networks combined with energy company asset management systems;

- customized consumer load management, lighting and climate control in buildings;

- predictive maintenance based on Building Information Modeling (BIM) and Facility Management (FM).

Electric cars remain a priority area of electrification in the majority of smart cities. The number of electric vehicles has been steadily growing: in 2011 there were 50000 electric cars in use across the world, and the number grew to $5 \mathrm{~m}$ by 2018 (Fig. 2). In some countries, for 


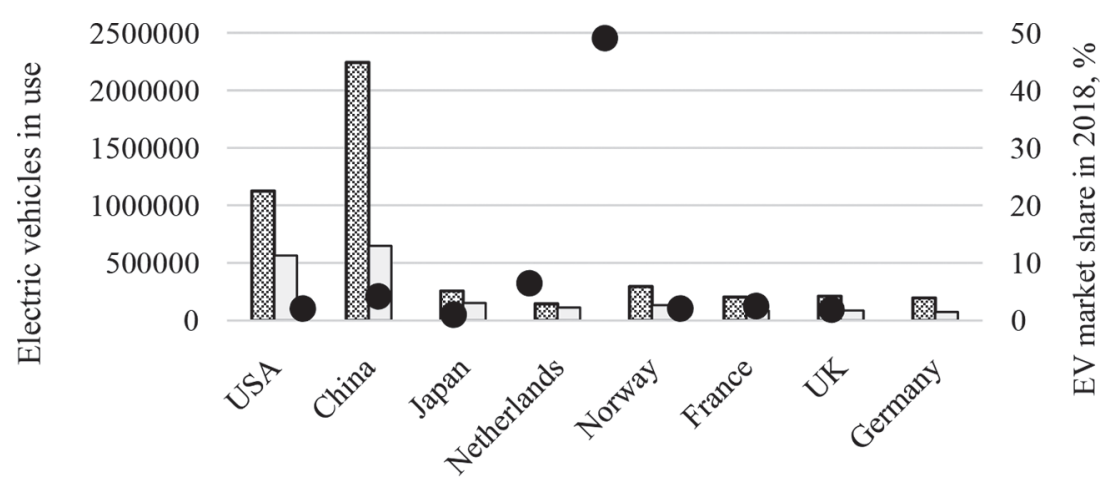

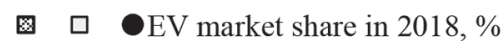

Figure 2: Electric vehicles in use worldwide.

example Norway and the Netherlands, laws were passed on a complete switchover to electric vehicles in the long-term run (by 2030-2040). The main trends in the industry are the expansion of EV charging stations and relevant infrastructure (e.g. 'smart parking lots'), production of components and spares for electric vehicles, as well as production of electric vehicles and light vehicles such as electric scooters and electric bicycles [23, 24].

Electric transport is already having an impact on the electricity market. In Great Britain, for example, owners of electric cars are able to sell power from their batteries back to the national grid as of 2016 thanks to a collaboration between car maker Nissan and international power group Enel [25]. This turns them into full-fledged and active participants in the energy market. Vehicle-to-grid (V2G) charging units and electric vehicles enable their owners to create mobile energy centers that connect their vehicles and the grid. The owners of Nissans Leafs, one of the market bestsellers, can be plugged in to charge during off-peak hours when electricity is cheap, and subsequently power their homes during periods of high prices or sell electricity back to the grid. Electric vehicles can therefore provide reliable capacity backup for an energy system with rapid response times. A similar pilot project was successfully implemented by Volkswagen Group, Lichtblick and SMA Solar Technology and Fraunhofer Institute Wind Energy and Energy System Technology in Germany in 2016 [26].

\section{CHANGES IN ENERGY SYSTEMS SERVING SMART DISTRICTS}

The case of the Akademichesky district of Yekaterinburg, one of the biggest residential development projects in Europe, has been considered with the purpose of analyzing specific measures aimed at solving the problem of a stable energy supply in a smart district. By 2026, the 2,500-hectare area will encompass $14 \mathrm{~m}$ square meters of housing, a medical school campus, several research institutions, production facilities, shopping malls and sporting centers (Fig. 3). The power layout of the district is presented in Fig. 4.

The construction of the Akademichesky district began in an area with a power surplus there is a right-of-way for 500/220/110 kV electric transmission lines nearby. Nevertheless, a decision was made to build two dedicated combined heat and power plants with heat output capacity of $800 \mathrm{Gcal} / \mathrm{h}$. Generating all thermal energy for the district's needs at boiler houses would contradict the principles of sustainable development. 

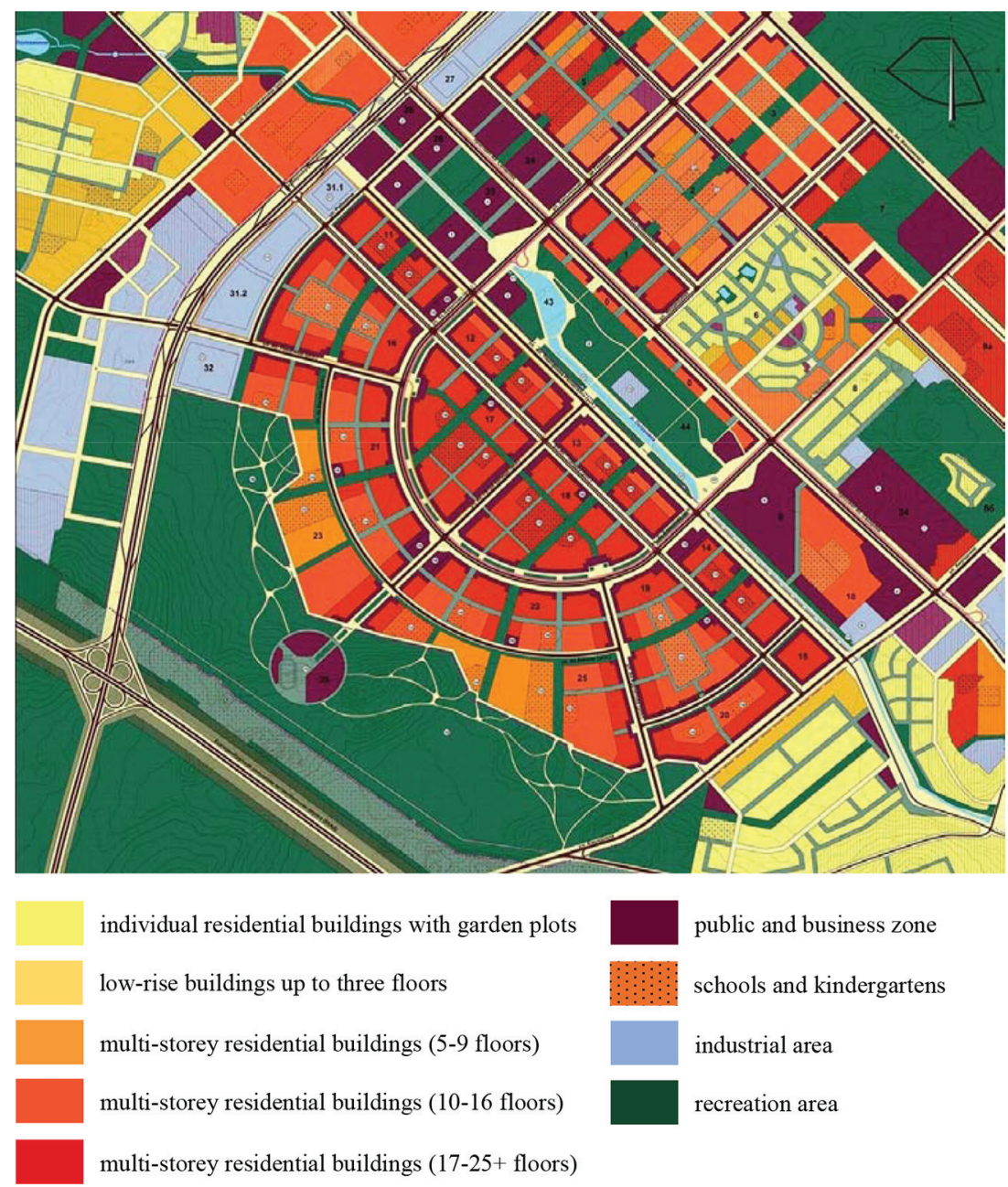

Figure 3: Master plan of Akademichesky district.

The first combined cycle power plant was built in consideration of the expected summertime thermal load of the district and the goal of maximizing the fuel use efficiency of the generator. Today it exceeds $90 \%$, with its electric efficiency reaching $55 \%$.

The district's power supply scheme is designed on the closed-loop principle (serving all category one power users), with a portion of CHP electric capacity delivered in the regeneration mode to avoid additional losses.

A second CHP was added to the project to meet the reliability requirements of category one power users and to avoid additional expenditures and heat losses because it would otherwise be necessary to have extremely large diameters of the district heating piping network to deliver the designed heating capacity. Today, both electric and thermal losses in the district networks do not exceed 3 to $4 \%$, complying with the highest world standards.

Since Akademichesky is first and foremost a residential area, one of the tasks that had to be addressed in the course of its construction was the creation of a chain of smart residential 


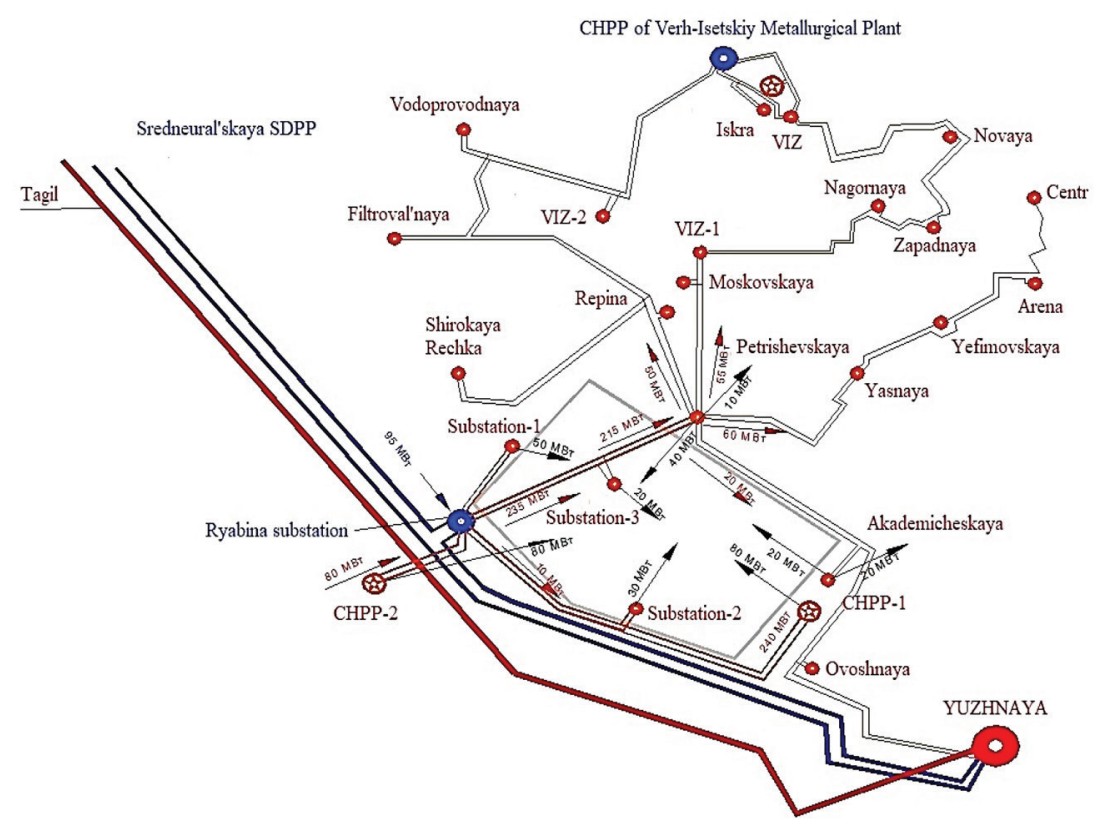

Figure 4: Power layout of the district.

buildings. The following conditions served as the guiding principles for designing 'a smart building':

- electrification of all processes - from microclimate systems to apartment (building) maintenance;

- automated control of electronic and household appliances and climate control systems, with intelligent mode control elements (on and off regimes, parameter setting, device reprogramming). Human involvement is therefore reduced to entering the operation sequence and monitoring performance using a smartphone or other portable devices;

- a fully electrified building makes the maximum use of energy saving devices and equipment (e.g. LED lighting).

At present, around $10 \%$ of households in the USA and $3 \%$ of households in Europe have smart building systems; the figure is to grow two- or three-fold in the next few years [27]. The penetration of smart home technology in Russia is now less than 1 percent. New residential buildings in Russia usually have different levels of home automation. An optimum configuration has been found in Akademichesky where flats are equipped with a security control system (a video intercom, a panic button, a fire alarm and suppression system) and a water detector. Home owners can have practically any Internet-of-Things services added to the system for a very small fee. The data collection and processing system of the building is a subsystem of the automatic process control system of energy suppliers. As a result, there is a single data base that receives data from households via in-flat utility meters.

Merging the digital technologies of infrastructure companies on one single smart platform for accounting, analysis and processing of information produces a colossal shared effect. For example, the intelligent vide surveillance system of the district can be used to both ensure 
dwellers' security and to monitor hazardous engineering infrastructure facilities, as well as for managing modern traffic services such as smart traffic lights. A modern apartment building subsequently starts to select the optimum combination of engineering technologies to meet the needs of its dwellers.

Electricity is increasingly used to either fully replace district heating or in combination with district heating even in case of optimum heating schemes. A separate question is the use of night time lower load periods to accumulate heat. Figure 5 presents a technical solution (that has yet to be implemented) that fits the ideology of sustainable development: a number of buildings in the district that use electric heating take advantage of cheaper electricity rates at night to accumulate heat in water heaters and concrete structures. Other buildings use a combination of conventional and electric heating. The solution is a product of a deep, systemic approach to all processes taking place in an apartment building. It is a known fact that the taller a building, the more difficult and costlier it is to supply heating to upper floors. Since interfloor overlappings and common areas are not heavily insulated, upper floors warm up by themselves. One only needs to heat up the floors by means of electric spot heating. Temperatures drop at night, so the electric heating is more intensive, yet the nominal capacity of the heat network does not increase.

Figure 6 presents a 24-hour curve of thermal energy supply for hot water heating. Naturally, the curve reflects the consumption of cold water by the dwellers of a specific building. However, electricity is required to pump water during peak consumption periods, so 24-hour electricity consumption curves practically replicate Fig. 6. The self-sufficient heat supply scheme that is used in Akademichesky made it possible to level out peaks by adding the 'hot water priority' function. This reduces the peak load and nominal thermal and electric capacity, which means the use of smaller diameter pipes and, therefore, lower investment spending. If additional water tanks are placed in buildings to cover peak water demand, electricity consumption will almost disappear.

There is one peculiar peak that does not depend on standard daily consumption. It occurs when the outside temperature exceeds $30^{\circ} \mathrm{C}$ and all air conditioners switch to maximum power. It is a seasonal feature that makes power generation by conventional installations economically inefficient due to the absence of thermal load. It has happened before that power supply systems of cities literally fell apart in such situations. In this context, it is

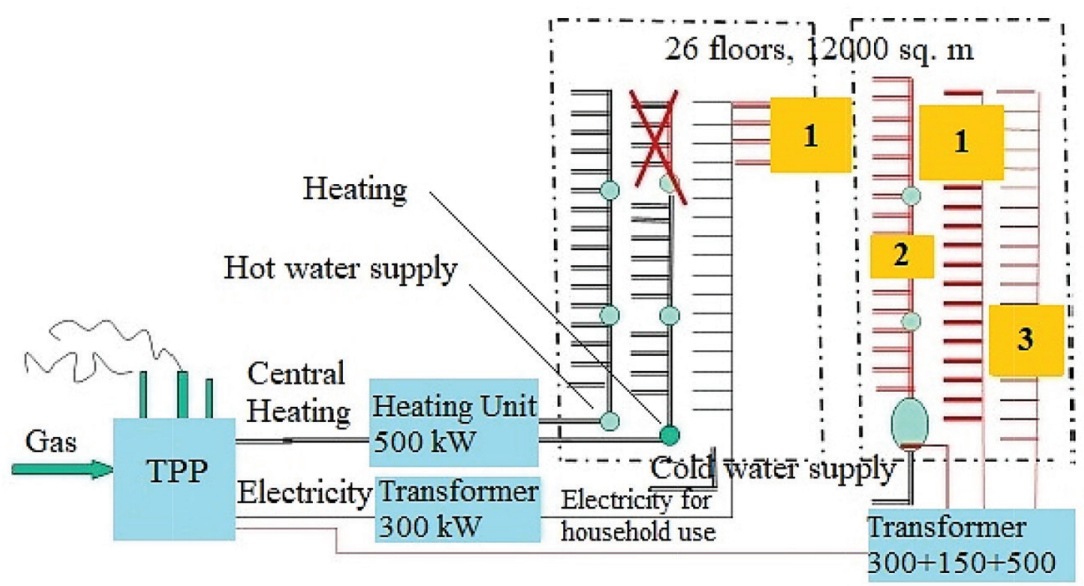

Figure 5: Possible uses of electric heating in district heating schemes; 1 - rechargeable electric heating, 2 - hot water supply, 3 - electricity for household needs. 


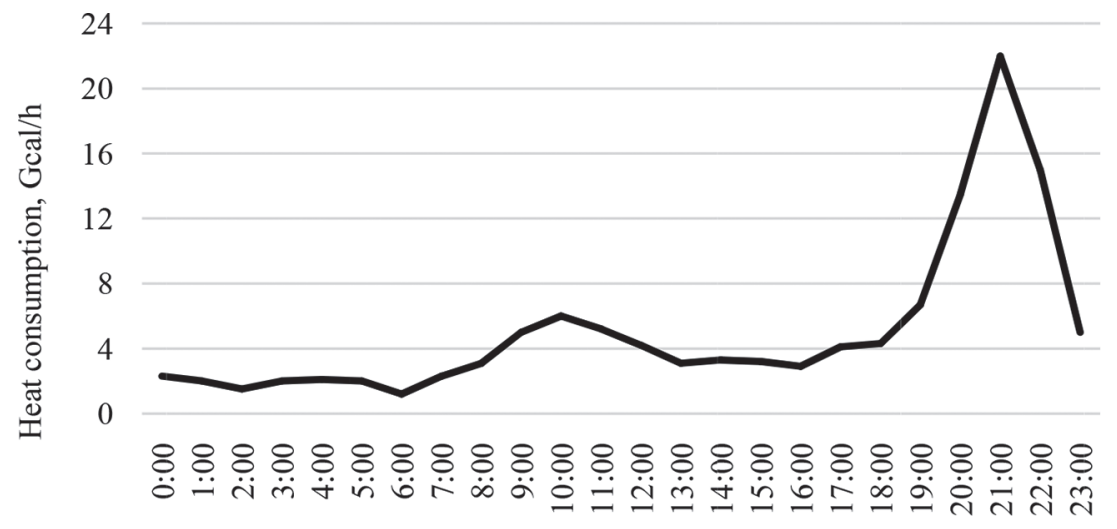

Figure 6: 24-hour curve of thermal energy supply for hot water heating.

appropriate to consider using absorption chillers that, first, consume ten times less electricity than conventional air conditions and, second, can use waste heat from a power generator instead of costly primary energy. A load based scheme combining absorption refrigeration with small CHP that is designed for a specific location could become an instrument of distributed generation that offers perfect economic and environmental characteristics and could considerably facilitate the operation of the entire urban system. Information technologies of the smart city will manage these processes using flexible tariffs and other solutions.

In order to level out the daily power supply profile as much as possible, it is necessary to increase night time power consumption. The most obvious solution would be electric vehicle charging, today's main trend in global car making. In Russia, though, a different trend is on the rise - that of natural gas vehicles, so the prospects of EV use in Russia are pretty much limited.

Stable power supply of smart buildings is accompanied by the emergence of new requirements for energy and capacity suppliers: the volume of new generating and grid capacity being put into service must match load growth; reliability of power supply must be backed by financial commitments; consistent electric power quality (voltage in particular); lower prices of electricity and capacity for smart buildings as compared to traditional buildings. In this regard, the following technological and economic solutions could be proposed.

1. A part of the energy system employing highly maneuverable generating installations could be dedicated specifically to servicing smart cities, especially at the initial stage of their growth. This means creating relevant infrastructure at the levels of operational dispatch and control and strategic planning for the purposes of accelerated smartization of the energy industry. The issue has been a subject of wide debate in the scientific and industrial community [28-30]. The authors agree that among the considerations in favor of this proposal are the pilot character of the relevant technologies, the opportunity to perfect the mechanisms of virtual power plant management; and a low commercial interest from large energy businesses.

2. Optimization of the structure of CHP by type of unit capacity of combined cycle installations with high power generation efficiency (for example, increasing the share of combined-cycle gas turbine installations).

3. Reduction of the power supply radius and of the length of the grid by using small and medium-sized generators. 
4. Ensuring optimum load distribution among generating units with automated configuration control of active equipment by, say, hour.

5. Use of energy saving house appliances and accumulators that are charged during the overnight load valleys (for example, for heating and hot water supply); installation of accumulators at generating facilities (the latter is a requirement for RES installations within the grid).

An important incentive for the development of smart cities is the price of electricity that is acceptable to various actors. Government energy pricing policy should wisely regulate the entire chain: the price of natural gas and the price ratio of gas to electricity; prices of energy equipment; the length of the grid, its transmission capacity and power losses.

The following options for cutting current expenses and capital expenditures are also available: reducing per-unit fuel use by improving the efficiency of heat and power installations; automation of technological processes while maintaining their optimum operational parameters; reducing per-unit capital investment and per-unit fixed expenses. This would minimize production cost variability in different operation modes, which is particularly relevant to households due to uneven load schedules). Use of highly maneuverable generating installations; optimum load distribution among generators within local energy systems depending on the demand side load and energy efficiency of connected installations (including RES); optimization of consumer load schedules.

It is necessary to stress that the tariff police need to be adapted to the new energy consumption patterns that are typical of smart territories. This means a wide range of differentiated energy tariffs; discounts for changing one's energy consumption pattern and subsidies for smart building consumers; introduction of an effective cost management mechanism at power plants and in grids that could help reduce the price for consumers.

\section{CONCLUSION}

The development of smart cities is a pronounced trend in today's new way of life in its broad sense. It combines cutting-edge technology, high living standards, environmental friendliness and increasingly intellectual infrastructure. A key factor to his development is the stability of the energy sector and its readiness to undertake a new stage of electrification, in which electricity penetrates practically all domestic, industrial and transportation systems and processes, thus radically increasing their controllability and making them 'greener'.

This study considers sector-specific solutions that would make it possible to develop an effective technological policy for energy supply to smart cities and mitigate various risks that emerge in the course of the implementation of the new stage of electrification.

When designing the energy system of a smart city and implementing electrification projects it is essential to consider appropriate and adequate technical and economic solutions. In addition to the issues covered in this article, the problem of bundling together individual generators into local energy systems with the goal of economic optimization of capacity utilization is of high interest to researchers. Another topic of current interest is demand side management programs that help improve the stability and reliability of the power supply and reduce the demand for smart installations along with bringing down capital and operating costs.

\section{ACKNOWLEDGEMENTS}

The work was supported by Act 211 of the Government of the Russian Federation, contract 02.A03.21.0006. 


\section{REFERENCES}

[1] Cocchia, A., Smart and digital city: A systematic literature review. Smart City. Progress in IS, eds. R. Dameri, \& C. Rosenthal-Sabroux. Springer: Cham, pp. 13-43, 2014. https://doi.org/10.1007/978-3-319-06160-3_2

[2] Buck, N.T. \& While, A., Competitive urbanism and the limits to smart city innovation: The UK future cities initiative. Urban Studies, 54, pp. 501-519, 2015. https://doi. org/10.1177/0042098015597162

[3] Glasmeier, A. \& Christopherson, S., Thinking about smart cities. Cambridge Journal of Regions, Economy and Society, 8(1), pp. 3-12, 2015. https://doi.org/10.1093/cjres/ rsu034

[4] Gabrys, J., Programming environments: environmentality and citizen sensing in the smart city. Environment and Planning D: Society and Space, 32, pp. 30-48, 2014. https://doi.org/10.1068/d16812

[5] Martina, C., Evans, J., Karvonen, A., Paskaleva, K., Yang, D. \& Linjordet, T., Smartsustainability: A new urban fix? Sustainable Cities and Society, 45, pp. 640-648, 2019. https://doi.org/10.1016/j.scs.2018.11.028

[6] Calderóna, C., Underwood, C., Yi, J., Mcloughlin, A. \& Williams, B., An area-based modelling approach for planning heating electrification. Energy Policy, 131, pp. 262-280, 2019. https://doi.org/10.1016/j.enpol.2019.04.023

[7] Bibri, S.E. \& Krogstie, J., Smart sustainable cities of the future: An extensive interdisciplinary literature review. Sustainable Cities and Society, 31, pp. 183-212, 2017. https:// doi.org/10.1016/j.scs.2017.02.016

[8] Thompson, E.M., What makes a city 'smart'? International Journal of Architectural Computing, 14, pp. 358-371, 2016. https://doi.org/10.1177/1478077116670744

[9] Jain, A. \& Bajpai, M., Use of green energy for smart city: A review. International Journal of Civil Engineering, 3(5), pp. 136-139, 2016.

[10] Meijer, A., Gil-Garcia, R. \& Bolivar M.P.R., Smart city research. Contextual conditions, governance models, and public value assessment. Social Science Computer Review, 34(6), pp. 647-656, 2015. https://doi.org/10.1177/0894439315618890

[11] Meijer, A. \& Bolivar, M.P.R., Governing the smart city: a review of the literature on smart urban governance. International Review of Administrative Sciences, 82, pp. 392-408, 2016. https://doi.org/10.1177/0020852314564308

[12] Gitelman, L.D., Management education for a sustainable electric power industry in the 21st century. WIT Transactions on Ecology and the Environment, 190(2), pp. 1197-1203, 2014. https://doi.org/10.2495/EQ141112

[13] Orchestrating infrastructure for sustainable Smart Cities. White Paper, 2014, http:// www.iec.ch/whitepaper/pdf/iecWP-smartcities-LR-en.pdf (accessed 14 June 2019).

[14] Pérez-Delhoyo, R., Mora, H. \& Paredes, J.F. Using social network data to improve planning and design of smart cities. WIT Transactions on The Built Environment, 179, pp. 171-178, 2018. https://doi.org/10.2495/UG180161

[15] Somayya, M. \& Ramaswamy, R., Amsterdam smart city (ASC): Fishing village to sustainable city. WIT Transactions on Ecology and the Environment, 204, pp. 831-842, 2016. https://doi.org/10.2495/SC160681

[16] March, H. \& Ribera-Fumaz, R., Smart contradictions: The politics of making Barcelona a Self-sufficient city. European Urban and Regional Studies, 23(4), pp. 816-830, 2014. doi: 10.1177/0969776414554488 
[17] Calvillo, C.F., Sánchez, A. \& Villar, J., Evaluation and optimal scaling of distributed generation systems in a smart city. WIT Transactions on Ecology and the Environment, 179, pp. 845-857, 2013. https://doi.org/10.2495/SC130722

[18] Brown, M.A. \& Southworth, A., Mitigating climate change through green buildings and smart growth. Environment and Planning, 40(3), pp. 653-675, 2008. https://doi. $\operatorname{org} / 10.1068 / \mathrm{a} 38419$

[19] Gitelman L.D., Gitelman, L.M. \& Kozhevnikov, M.V., Window of opportunity for sustainable energy. International Journal of Energy Production and Management, 2(2), pp. 173-185, 2017. https://doi.org/10.2495/EQ-V2-N2-173-185

[20] Gitelman L.D., Gitelman, L.M. \& Kozhevnikov, M.V., Factoring environment into electrification management in a region. International Journal of Sustainable Development and Planning, 13(4), pp. 707-717, 2018. https://doi.org/10.2495/sdpv13-n4-707-717

[21] Kenworthy, J.R., The eco-city: Ten key transport and planning dimensions for sustainable city development. Environment \& Urbanization, 18, pp. 67-85, 2006. https://doi. org/10.1177/0956247806063947

[22] Perez, S.M. \& Auriault, C., Green business models for an electrical solution in buildings. WIT Transactions on Ecology and the Environment, 224, pp. 127-134, 2017. https://doi.org/10.2495/ESUS170121

[23] Papadopoulos, P., Akizu, O., Cipcigan, L.M., Jenkins, N. \& Zabala, E., Electricity demand with electric cars in 2030: Comparing great Britain and Spain. Proceedings of the Institution of Mechanical Engineers, 225, pp. 551-566, 2011.

[24] Global EV Outlook 2019, Paris: IEA, 2019, https://www.iea.org/publications/reports/ globalevoutlook2019/ (accessed 14 June 2019).

[25] The Smart City Market: Opportunities for the UK. Research Paper, 2013, https:// www.gov.uk/government/uploads/system/uploads/attachment_data/file/249423/bis13-1217-smart-city-market-opportunties-uk.pdf (accessed 14 June 2019)

[26] The Future of the German Automotive Industry. Structural Change in the Automotive Industry: Challenges and Perspectives, http://library.fes.de/pdf-files/wiso/12165.pdf (accessed 14 June 2019).

[27] Lobaccaro, G., Carlucci, S. \& Löfström, E., A review of systems and technologies for smart homes and smart grids. Energies, 9, pp. 348-380, 2016. https://doi.org/10.3390/ en9050348

[28] Sarfi, R.J., Shafer, J.R. \& Gemoets, L.A., New energy delivery models for communities: how utilities can transform their delivery models to meet the needs of their stakeholders, short and long term. International Journal of Energy Production and Management, 3(2), pp. 132-143, 2018. https://doi.org/10.2495/EQ-V3-N2-132-143

[29] Gaspari, J., Boulanger, S.O.M. \& Antonini, E., Multi-layered design strategies to adopt smart districts as urban regeneration enablers. International Journal of Sustainable Development and Planning, 12(8), pp. 1247-1259, 2017. https://doi.org/10.2495/SDPV12-N8-1247-1259

[30] Scholten, D. \& Künneke, R., Towards the comprehensive design of energy infrastructures. Sustainability, 8(12), p. 1291, 2016. https://doi.org/10.3390/su8121291 